\title{
Individual QT-R-R Relationship: Average Stability over Time Does Not Rule Out an Individual Residual Variability: Implication for the Assessment of Drug Effect on the QT Interval
}

\author{
Fabrice Extramiana, M.D., ${ }^{*}$ Pierre Maison-Blanche, M.D., ${ }^{*}$ Fabio Badilini, Ph.D., $\dagger$ \\ Philippe Beaufils, M.D., ${ }^{*}$ and Antoine Leenhardt, M.D.* \\ From the * Lariboisière Hospital, Paris, France; and †AMPS LLC, New York, NY
}

\begin{abstract}
Background: Universal QT correction formulae have been shown to under or overcorrect the QT interval duration. Individual QT-R-R modeling has been proposed as a preferable solution for heart rate correction of QT intervals. However, the QT-R-R relationship stability over time needs to be evaluated.

Methods: The present report is part of randomized, double-dummy, and placebo-controlled 4way crossover phase 1 study (48 healthy volunteers). Each randomized period included a run-in placebo day followed the day after by drug administration, with moxifloxacin as a positive control for QT interval measurement. Digital Holter ECG data were analyzed using the "bin" approach. For each period, individual QT-R-R relationship were calculated using two different models (linear and parabolic log-log models).

Results: The mean intrasubject variability for the $\alpha$ coefficient of the linear modeling (SDintra $=$ $0.011 \pm 0.005)$ reached $28.6 \pm 10.2 \%$. When the parabolic model was considered, the SDintra was $0.026 \pm 0.009$ for the $\alpha$ coefficient. The QT-R-R relationship variability was in part related to long-term RR changes $\left(\mathrm{R}^{2}=30 \%, \mathrm{P}<0.05\right)$. However, no significant time effect (ANOVA) was evidenced for QT-R-R coefficients. Moxifloxacin significantly increased the $\alpha$ coefficient of the QT$\mathrm{R}-\mathrm{R}$ relationship from $0.07 \pm 0.018$ to $0.085 \pm 0.019, \mathrm{P}<0.05$ (linear model).

Conclusions: The individual QT-R-R relationship shows a residual variability in part related to long-term autonomic changes. In addition, the QT-R-R relationship might be modulated by the drug tested. As a consequence, pretherapy QT-R-R relationship obtained in a given patient cannot be used as a fingerprint throughout a drug trial.
\end{abstract}

A.N.E. 2005;10(2):169-178

Ventricular repolarization (and consequently the QT interval) has the intrinsic property of being inversely related to heart rate (HR) (i.e., QT interval shortened as heart rate increases). ${ }^{1,2}$ As a consequence, an evaluation of QT-interval changes must always accommodate for the underlying changes in HR. Many general HR correction formulae have been proposed to normalize the QT to HR using several mathematical functions to correct for HR changes. ${ }^{3,4}$ The "corrected" QT value known as the QTc interval is thus intended to represent the QT interval at a standardized heart rate of $60 \mathrm{bpm}$.
However, ventricular repolarization is influenced by rate-independent factors such as sex hormones, ${ }^{5,6}$ the autonomic nervous system activity, ${ }^{7-12}$ genetic background of transmembrane channel functions ${ }^{13}$, or cardiac diseases. ${ }^{14}$ For instance, population studies have shown that women have longer QT interval than males ${ }^{15,16}$ and that the QT interval is prolonged during sleep. ${ }^{12,17}$

Hence, the concept of a "universal" (i.e., valid for any individual) correction formulae is highly questionable. Actually, these "universal" correction formulae are discredited since they have been

Address for reprints: Fabrice Extramiana, M.D., Cardiology Department_Lariboisière Hospital 2 rue Ambroise Paré, 75475 Paris Cedex 10, France. Fax: +33-1-49-95-84-39; E-mail: fabrice.extramiana@lrb.ap-hop-paris.fr

Fabrice Extramiana was supported by a grant from the "Groupe de Réflexion sur la Recherche Cardio-vasculaire." 
shown to over-correct or under-correct the QT interval when HR moves away from average, resting ranges. ${ }^{4,18}$

Population-specific correction formula have been proposed as a potential alternative solution., ${ }^{4,5,19}$ This method is based on a single ECG sample per subject but a broad cohort. Each subject is characterized by a pair data [QT:RR] and the mathematical modeling of the QT-R-R relationship applied on the pooled data is used to calculate the population-specific correction QT interval (QTcN). Still it was shown that the population-specific approach does not describe adequately all individual data ${ }_{1}^{19,20}$ so the concept of a subject-specific correction formula (QTcNi) was proposed in order to minimize the correction error. ${ }^{20}$ In contrast to the population-specific approach, this method is based on multiple ECG samples at different HRs obtained within the same subject, that are further used to determine the QT-R-R relationship for that individual.

It has been suggested that the individual QT-R$R$ relationship could be stable over time in healthy subjects and thus could be considered as a fingerprint. ${ }^{20,21}$ However, data from Batchvarov et al. have only shown that in healthy subjects the intersubject variability of the QT-R-R relationship is higher than the intrasubject one. ${ }^{22}$

The individual QT-R-R relationship is modulated by short-term ${ }^{23,24}$ and mid-term subtle HR changes patterns and autonomic variations as well. For instance, the QT-R-R relationships is steeper during the day than at night, ${ }_{1}^{17}$ and is impaired in diabetic patients with cardiac autonomic neuropathy. ${ }^{25}$ The mean HR of a given period of observation also influences the steepness of the QT-R-R relationship. ${ }^{17,26}$

Consequently, providing thorough data on individual QT-R-R models is still needed.

Many noncardiovascular drugs have been withdrawn from the market for induction of Torsades de Pointes, although the amount of QT prolongation in clinical studies was on average small. ${ }^{27}$ Recently, regulatory agencies have required ECG processing techniques with the ability of detecting small (i.e., $5 \mathrm{~ms}$ ) drug-induced QT interval prolongation. ${ }^{28}$

Keeping in mind the $5 \mathrm{~ms}$ challenge, it is of critical interest to determine whether the intrasubject variability of the QT-R-R relationship, if any, is able to mask such small drug-induced QT interval changes.

The aim of the present study was three fold: (1) to assess the individual QT-R-R relationship vari- ability, (2) to test the hypothesis that this variability is related to long-term heart rate changes, and (3) to evaluate the influence of the individual QT-R$\mathrm{R}$ relationship variability on QT interval measurement stability.

\section{SUBJECTS AND METHODS}

\section{Study Design}

The data reported in the present article are part of the study designed as a 4-way crossover study assessing two single doses of alfuzosin versus placebo and moxifloxacin (400 $\mathrm{mg}$ ) as a positive control. The study was a single-center, randomized, doubledummy, and placebo-controlled, in 48 healthy volunteer males aged 22-40 years.

In this study, ECG monitoring was performed using continuous 24-hour Holter recorders.

Each subject took a run-in placebo the day before drug administration. This run-in placebo period was used as the baseline period for each drug arm. The time interval between run-in placebo and treatment was only 24 hours. Four 24-hour Holter ECG were obtained 1 week apart under placebo (named week 1, week 2, week 3, and week 4). One randomly assigned period included a run-in placebo followed by moxifloxacin administration.

The study was approved by the ethics committee of the Ambroise Paré Hospital (Boulogne Billancourt, France), and the subjects signed an informed consent form.

\section{Holter Monitoring}

ECG analysis was performed over a 4-hour period (3-7 p.m.) corresponding to the expected peak plasma concentration of the tested drugs.

Analysis was performed using a subject-specific protocol of time matched ECGs. The on-treatment data were compared to run-in placebo data during that 4-hour time window. ECG readers were blinded to treatment.

HR parameters included the mean HR during the 4-hour period (HR4-RR4), the mean HR during the day (HRday) and the mean HR during the entire recording (HR24). Of note, subjects were confined in supine or semi-recumbent position for at least 12 hours, thus allowing ECG collection in stable conditions. 


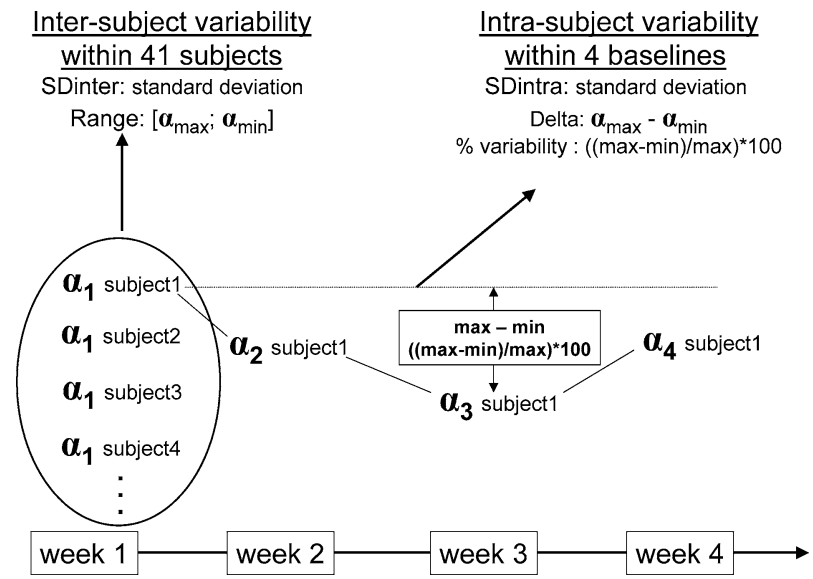

Figure 1. The intersubject variability was described using the range and the standard deviation between subjects for the same period (SDinter). The intrasubject variability within different periods was assessed by using the standard deviation of the measures (SDintra), the delta (maximum minus minimum values) and the percent change $([(\max -\min ) / \max ) \times 100])$.

ECG waveforms were digitally recorded (Syneflash Digital recorder, ELA Medical) and analyzed using WinAtrec v4.0.0 (AMPS LLC, NY). This software is intended to provide a tool to build templates for QT analysis from Holter recordings. Validation of the algorithm for obtaining averaged ECG templates has been previously described. ${ }^{29}$

Data processing was performed in three steps: (1) $\mathrm{RR}$ interval measurements, (2) classification of all sinus cardiac ECG complexes into $10 \mathrm{~ms}$ RR groups ("bins"), and (3) averaging of complexes within each RR bin and measurement of QT intervals. The QT interval length of the averaged complex was the value for each subject in each treatment group (or period) used in the analysis. The data were processed in a blinded manner.
For each subject and each period, the QT interval duration at each RR interval were used to calculate the QT-R-R relationship using two different models (linear model: $\mathrm{QT}=\alpha \times \mathrm{RR}+\beta$ and parabolic loglog model: $\mathrm{QT}=\beta \times \mathrm{RR}^{\alpha}$ ). For each model, the residual sum of square (RSS) was calculated. The model with the lowest RSS $\left(\mathrm{ms}^{2}\right)$ was considered as the model providing the best fit of the QT-R-R relationship.

QT1000 intervals (QT interval duration at $\mathrm{RR}=$ $1000 \mathrm{~ms}$ ) were calculated from each of the two models (linear and parabolic log-log).

\section{Statistical Analysis}

Results are presented as mean $\pm \mathrm{SD}$. The intersubject variability was described using the range (maximum minus minimum values) and the standard deviation between subjects for the same period (SDinter) (Fig. 1). The intrasubject variability within different periods was assessed by using the standard deviation of the measures (SDintra), the delta (maximum minus minimum values) and the percent change $([(\max -\min ) / \max ) \times 100])$ (Fig. 1).

The hypotheses of systematic trends in variability within methods, over time and after drug administration were assessed by ANOVA for repeated measures with Scheffe's post tests when applicable.

Correlation between quantitative variables was evaluated using a linear regression modeling.

A $P$ value less than 0.05 was considered as significant.

\section{RESULTS}

A good quality for each of the five recordings (four run-in placebo and moxifloxacin) was found in 41 subjects. The average number of QT "bins" was around 50, thus covering a $500 \mathrm{~ms}$ RR interval range (Table 1).

Table 1. Number of OT Bins and Heart Rate

\begin{tabular}{|c|c|c|c|c|}
\hline & \multirow{2}{*}{$\frac{\text { Number of QT Bins }}{\text { Mean } \pm \text { SD (range) }}$} & \multicolumn{3}{|c|}{ Heart Rate } \\
\hline & & HR24 & HRday & HR4 \\
\hline Week 1 & $53 \pm 9 *(34 ; 68)$ & $64 \pm 9$ & $63 \pm 9$ & $63 \pm 9$ \\
\hline Week 2 & $51 \pm 9(32 ; 65)$ & $63 \pm 8^{*}$ & $62 \pm 9$ & $61 \pm 9^{*}$ \\
\hline Week 3 & $53 \pm 9 *(34 ; 67)$ & $63 \pm 8^{*}$ & $62 \pm 8^{*}$ & $60 \pm 7 * \dagger$ \\
\hline Week 4 & $53 \pm 9 *(35 ; 68)$ & $63 \pm 8^{*}$ & $62 \pm 7^{*}$ & $60 \pm 7 * \dagger$ \\
\hline Moxifloxacin & $49 \pm 9(33 ; 66)$ & $65 \pm 8$ & $64 \pm 8$ & $64 \pm 8$ \\
\hline
\end{tabular}

$* \mathrm{P}<0.05$ versus moxifloxacin.

${ }^{\dagger} \mathrm{P}<0.05$ versus week 1. 


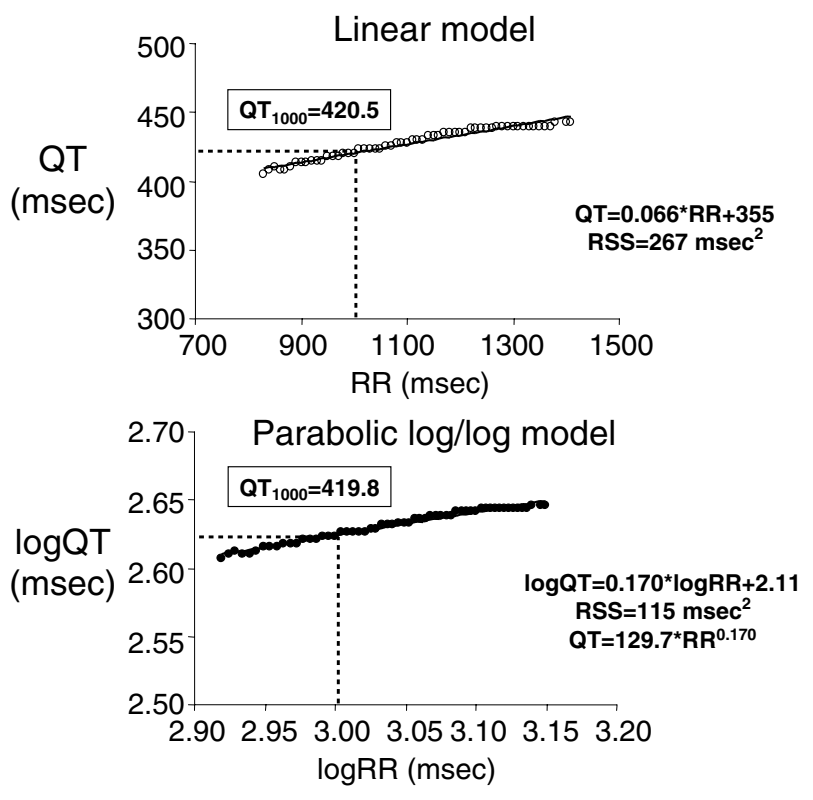

Figure 2. Linear (upper panel) and parabolic log-log modeling of the individual QT-R-R relationship in one subject. Although parabolic log-log model led to a smaller residuum sum of square, the degree of curvature of QT-R-R plots was small leading to pseudo-linear relationships.

The mean HR was not different within the four placebo periods with the exception of HR4 of week 1 , which was higher when compared to weeks 3 and 4. Moxifloxacin was associated with a weak $(<2 \mathrm{bpm})$ albeit significant increase in HR4, HRday, and HR24 (Table 1).

The values of RSS $\left(\mathrm{ms}^{2}\right)$ obtained for the linear model were higher than those of the parabolic log$\log$ model. This finding was consistent during the 5 Holter periods (Table 2).
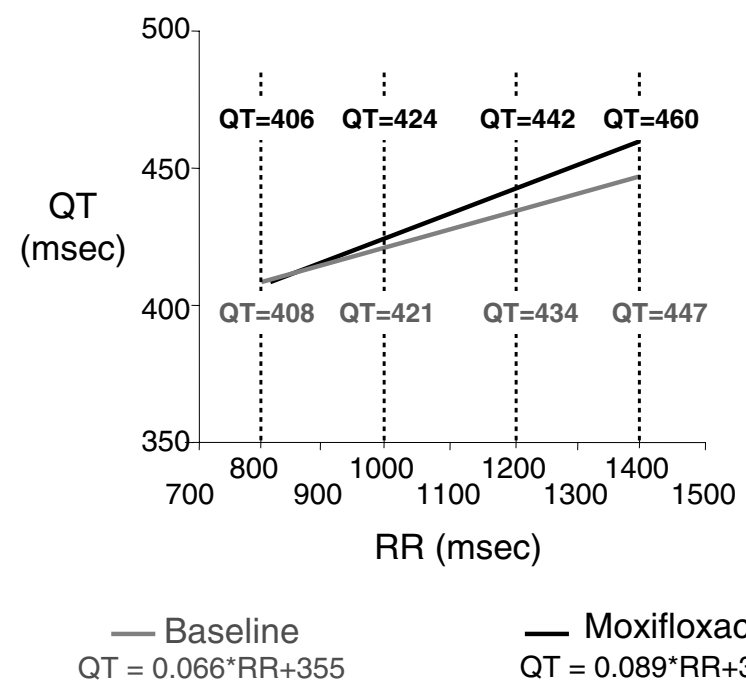

$$
\text { - Moxifloxacin }
$$

Figure 3. QT-R-R relationship using the linear model under baseline condition (gray line) and after moxifloxacin (black line). The values of the calculated OT interval duration at $\mathrm{RR}=800,1000,1200$, and $1400 \mathrm{~ms}$ are indicated above the curves on moxifloxacin and below the curves under baseline condition.

Figure 2 shows that the degree of curvature of QT-R-R plots was rather small leading to pseudolinear relationships.

Table 2 also gives the mean coefficients of the QT-R-R relationships during the four periods, and on moxifloxacin (linear and parabolic log-log). Figure 3 shows one typical example of the QT-R-R relationship (linear model) under baseline condition and after moxifloxacin. Moxifloxacin significantly increased the $\alpha$ coefficient of the QT-R-R relationship regardless of the mathematical formula, although less consistently for the log-log parabolic model (Table 2).

Table 2. Residuam, $\alpha$ and $\beta$ Coefficient of the OT Rate-Dependence

\begin{tabular}{|c|c|c|c|c|c|c|}
\hline & \multicolumn{2}{|c|}{$\mathrm{RSS}\left(\mathrm{ms}^{2}\right)$} & \multicolumn{2}{|c|}{$\begin{array}{l}\text { QT Rate-Dependence } \\
\alpha \text { Coefficient }\end{array}$} & \multicolumn{2}{|c|}{$\begin{array}{l}\text { QT Rate-Dependence } \\
\beta \text { Coefficient }\end{array}$} \\
\hline & $\begin{array}{l}\text { Linear } \\
\text { Model }\end{array}$ & $\begin{array}{l}\text { Parabolic } \\
\text { Model }\end{array}$ & $\begin{array}{l}\text { Linear } \\
\text { Model }\end{array}$ & $\begin{array}{l}\text { Parabolic } \\
\text { Model }\end{array}$ & $\begin{array}{l}\text { Linear } \\
\text { Model }\end{array}$ & $\begin{array}{l}\text { Parabolic } \\
\text { Model }\end{array}$ \\
\hline Week 1 & $243.3 \pm 303$ & $161.9 \pm 168^{\dagger}$ & $0.073 \pm 0.018^{*}$ & $0.175 \pm 0.036^{*}$ & $330 \pm 29^{*}$ & $123.7 \pm 29.6$ \\
\hline Week 2 & $178.2 \pm 128$ & $114.3 \pm 89^{\dagger}$ & $0.072 \pm 0.020^{*}$ & $0.174 \pm 0.038^{*}$ & $332 \pm 31 *$ & $125.2 \pm 31.5$ \\
\hline Week 3 & $209.5 \pm 180$ & $138.2 \pm 128^{\dagger}$ & $0.074 \pm 0.018^{*}$ & $0.181 \pm 0.036$ & $330 \pm 30^{*}$ & $119.5 \pm 30.6$ \\
\hline Week 4 & $278.9 \pm 362$ & $147.2 \pm 168^{\dagger}$ & $0.071 \pm 0.014^{*}$ & $0.173 \pm 0.031^{*}$ & $333 \pm 28^{*}$ & $122.3 \pm 33.6$ \\
\hline Moxifloxacin & $306.1 \pm 360$ & $196.5 \pm 270^{\dagger}$ & $0.085 \pm 0.019$ & $0.196 \pm 0.039$ & $323 \pm 29$ & $108.7 \pm 28.9$ \\
\hline
\end{tabular}

$* \mathrm{P}<0.05$ versus moxifloxacin.

${ }^{\dagger} \mathrm{P}<0.05$ versus linear model. 
Table 3. Calculated OT1000 Interval

\begin{tabular}{lll}
\hline & $\begin{array}{c}\text { Linear } \\
\text { Model }\end{array}$ & $\begin{array}{c}\text { Parabolic } \\
\text { Model }\end{array}$ \\
\hline Week 1 & $402 \pm 22^{*}$ & $402 \pm 22^{*}$ \\
Week 2 & $403 \pm 24^{*}$ & $403 \pm 24^{*}$ \\
Week 3 & $404 \pm 21^{*}$ & $404 \pm 21^{*}$ \\
Week 4 & $404 \pm 22^{*}$ & $404 \pm 22^{*}$ \\
Moxifloxacin & $409 \pm 22$ & $409 \pm 22$ \\
\hline
\end{tabular}

$* P<0.05$ versus moxifloxacin.

No significant time effect as assessed using ANOVA was evidenced for either RSS and QT-R-R relationship coefficient (Table 2).

Table 3 shows the mean calculated QT1000 intervals for each statistical model and at each time points. Notwithstanding of different fittings, the linear and parabolic log-log models yielded similar QT1000 interval values. QT intervals at each time point were nearly the same from week 1 to week 4. Moxifloxacin significantly increased the QT1000 interval (Table 3). The moxifloxacininduced QT1000 interval prolongation ranged from 5 to $7 \mathrm{~ms}$ depending on the period and the fitting model. However, because of the moxifloxacininduced increase of the steepness of the QT-R-R relationship, the QT interval change was related to the heart rate considered. As shown in the example displayed in Figure 3, moxifloxacin had no effect on QT interval duration at $\mathrm{RR}=800 \mathrm{~ms}$, whereas its QT prolonging effect reached $10 \mathrm{~ms}$ at the slowest heart rates recorded.

Despite the absence of statistically significant time effect, a substantial individual variability of QT rate-dependence could be detected (individual linear coefficients of the QT-R-R relationships are given in Appendix 1).

The $\alpha$ coefficient of the linear model ranged from 0.039 to 0.124 within the 41 subject cohort. The inter-subject variability assessed by standard deviation of the mean was $0.018,0.020,0.018,0.014$ for weeks 1-4, respectively.

The mean intrasubject variability for the $\alpha$ coefficient of the linear modeling (SDintra $=0.011 \pm$ $0.005)$ although lower than the inter-subject variability reached $28.6 \pm 10.2 \%$. More specifically, SDintra ranged 0.008-0.059.

When the parabolic model was considered, the SDintra were $0.026 \pm 0.009$ (range $0.011 ; 0.132$ ) for the $\alpha$ coefficient and $21.9 \pm 7.9$ for the $\beta$ coefficient.
Appendix 2 shows individual QT1000 interval values obtained using the linear model. The mean intra-subject variability for QT was $5.1 \pm 2.4$ ms. The mean individual delta QT1000 observed within the four baseline periods was $11.5 \pm 5.7 \mathrm{~ms}$ (i.e., larger than the average moxifloxacin-induced QT1000 prolongation).

Appendix 2 also shows the distribution of the moxifloxacin effect on QT interval. Using categorical analysis, moxifloxacin induced a QT1000 interval prolongation greater than $1 \mathrm{~ms}$ in 19 subjects, a QT change less than $1 \mathrm{~ms}$ in 6 subjects, but a shortening in the remaining 16 subjects (the mean drug effect is shown in Table 2).

The residual variability in the QT-R-R relationship (and consequently in QT1000 interval duration) were in part related to changes in HR4. Figure 4 shows the relationship between the linear coefficient $\alpha$ and the global HR of the period considered in two representative subjects. Stable HR4 interval was associated with stable QT-R-R relationship, whereas HR4 increase was associated with a higher $\alpha$ coefficient of the linear relation. Figure $5 \mathrm{~A}$ shows the relationship between the linear $\alpha$ coefficient and RR4. The $\alpha$ coefficient increased as the RR4 decreased (i.e., HR4 increased). Changes in RR4 could explain about $30 \%\left(\mathrm{R}^{2}\right)$ of $\alpha$ coefficient changes.

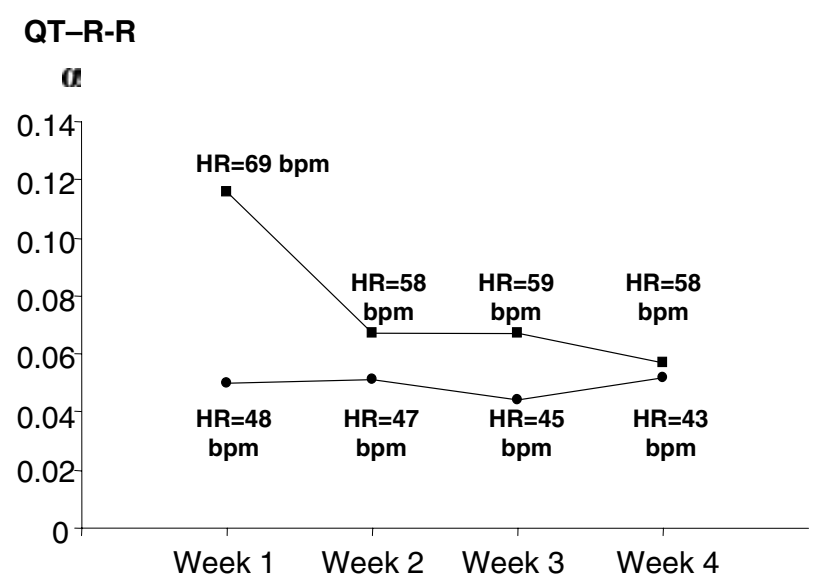

Figure 4. Relationship between the linear coefficient $\alpha$ and the global HR of the period considered in two representative subjects. Stable HR4 interval was associated with stable QT-R-R relationship (circles), whereas HR4 increase was associated with a higher $\alpha$ coefficient of the linear relation (squares). $\mathrm{HR}=$ heart rate; $\mathrm{bpm}=$ beat per minute 


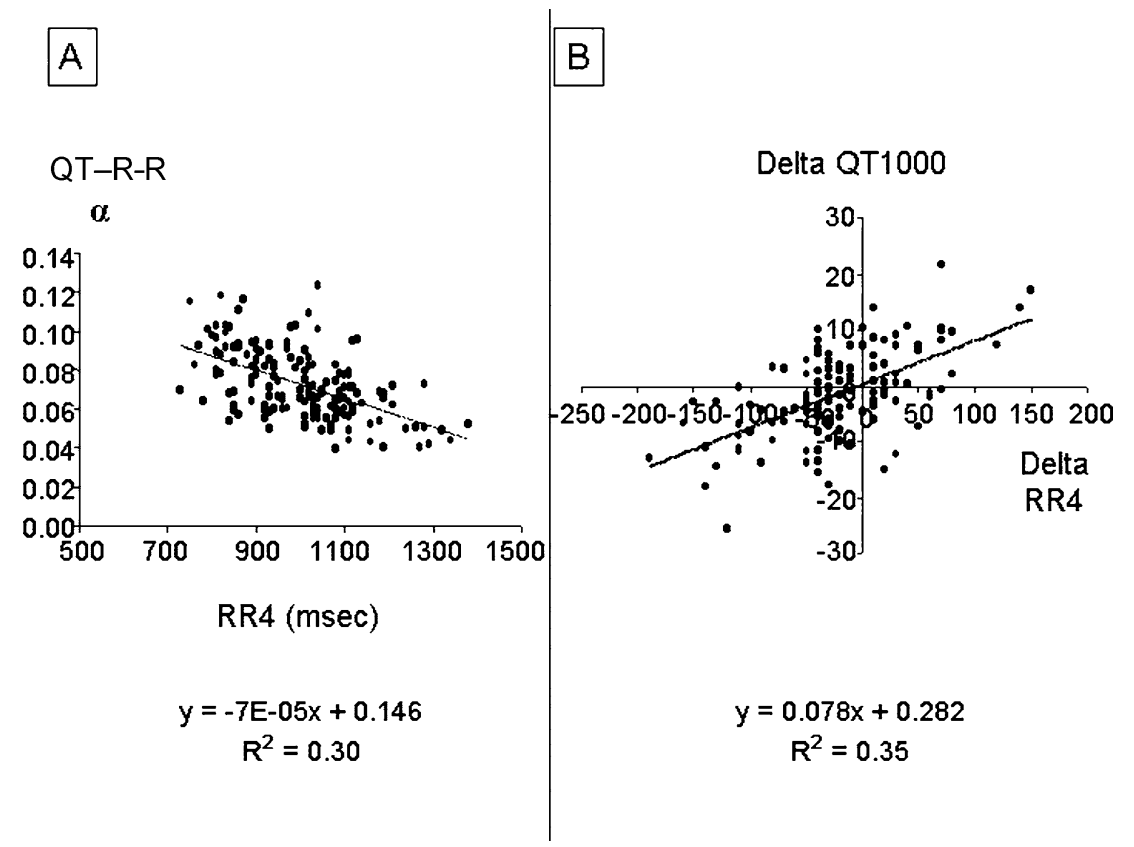

Figure 5. (A) Relationship between the linear $\alpha$ coefficient and RR4. The $\alpha$ coefficient increased as the RR4 decreased. Changes in RR4 could explain about 30\% ( $\mathrm{R}^{2}$ ) of $\alpha$ coefficient changes. (B) The delta QT1000 interval change within periods was also significantly correlated with the change in RR4. Thirtyfive percent of QT1000 variability could be explained by RR4 changes.

The delta QT1000 interval change within periods was also significantly correlated with the change in RR4 (Fig. 5B). Thirty-five percent of QT1000 variability could be explained by RR 4 changes.

\section{DISCUSSION}

The present study confirms that the average QT$\mathrm{R}-\mathrm{R}$ relationship can be considered as stable over time when a homogeneous cohort of subjects is considered. However, our data indicate that apparent average stability is associated with a residual individual variability in the QT-R-R relationship. Another finding is the importance of long-term heart rate factor for QT-R-R relationship assessment.

In this study, the QT1000 variability derived from individual QT-R-R relationship does not blur a small drug-induced QT prolongation.

The evaluation of the individual QT-R-R relationship has been proposed to overcome the systematic biases induced by any "universal" correction formula. ${ }^{20,22}$ The best mathematical model to describe this relationship has been debated. ${ }^{20,22,30}$ We have previously demonstrated that the linear modeling provides good fittings of the QT-R-R relationship when the QT interval is measured in stable heart rate conditions and separately during the day and at night. ${ }^{17}$ Malik et al. demonstrated that the linear modeling can be considered as a good regression model, though the arcus hyperbolic sine and the shifted logarithmic models could lead to lower residual. ${ }^{20,22}$ The duration of the period used to determine the QT-R-R relationship is also important. Since the QT-R-R relationship is influenced by the autonomic nervous system, mixing data from different circadian periods can affect the linearity of the relationship. A single modeling of two different linear relationships (i.e., diurnal and nocturnal) would be better fitted using a nonlinear model. In this study, the parabolic log-log model only provided negligible fitting improvement. This finding could be related to the imposed supine position following drug administration, thus making HR more stable. ${ }^{23}$ The differences between the two mathematical models did not result in significant 
differences of the QT interval duration in controlled conditions, and both the methods were sensitive enough to detect the small QT interval prolongation induced by moxifloxacin. ${ }^{31}$ Therefore, the added value of non-linear mathematical modeling appears to be limited.

In accordance with a previous study, we found that the inter-subject variability of the QT-R-R relationship is higher than the intrasubject one. ${ }^{22}$ However, descriptive statistics evidenced an intrasubject variability around $30 \%$ over the four placebo periods. Co-variables such as gender, age, and cardiac abnormalities are known to change the QT$\mathrm{R}-\mathrm{R}$ relationship between subjects. ${ }^{17,32,33}$ In a single subject, the QT-R-R relationship is modulated by the autonomic nervous system, the mean RR interval, decreased by beta-blockers and increased by blockers of the IKr current. ${ }^{17,34,35}$ In the present study, we confirm the significant correlation between the QT-R-R relationship and the global mean RR interval of the period considered. ${ }^{17,26}$

Despite substantial intra-subject variability, ANOVA did not evidence consistent changes in the QT-R-R relationship over time. These apparently conflicting data suggest that at least part of the intrasubject variability displays random properties, i.e., random distribution of ANS and long-term RR interval changes. However, it is tempting to speculate that a random distribution of those modulating factors is not granted in a given trial. A systematic bias in heart rate changes could conceal the stability of the QT-R-R relationship over time. Therefore, for studies with a crossover design, a single evaluation of the QT-R-R relationship would be appropriate only in the case of stability of the ANS influences and global HR at each step of the study.

In addition, moxifloxacin significantly increased the steepness of the QT-R-R relationship. Since experimental studies show that moxifloxacin interacts with repolarizing currents, that result was somewhat expected. ${ }^{35}$ As a consequence, the QT-R-R relationship evaluation should be assessed again when the drug studied is associated with changes in RR interval, autonomic modulation, hormonal status, and/or a blockade of the IKr current.

Provided that the QT-R-R relationship can be considered as stable in a subset population of normal subjects, the calculated QT1000 interval is expected to show a similar behavior.

In this study, descriptive statistics reported a mean individual delta QT1000 above $10 \mathrm{~ms}$. However, no consistent change over time was evidenced using ANOVA, again suggesting that the individual variability is related to a random phenomenon. We show that the delta QT1000 interval change is significantly correlated with the change in mean RR interval that seems to be randomly distributed. The QT1000 interval duration variability was not able to mask the small QT interval prolongation induced by moxiflocacin.

We made use of the QT1000 interval mainly because it is the easiest to compare with the widely used QTc values. In addition, the choice of the QT1000 interval was possible in this study, because subjects were at rest during Holter recordings. Thus, the relatively slow heart rate of 60 bpm could be recorded on both baseline condition and after moxifloxacin. The use of QT1000 may introduce an error if the tested compound lead to more dramatic changes in heart rate. Then the QT-R-R relationship would be computed for different ranges of heart rate. Assessing the QT prolongation would require interpolating one model and thus introduce an unknown error. However, the choice of the QT1000 value is not mandatory. One of the advantage of the bin method is its ability to compare QT interval duration for any of the RR interval recorded on each protocol arm. This point is of particular importance for instance in infants, in patients with slow or high heart rates, as well as for drugs inducing a marked tachycardia.

We conclude that the simple linear modeling of the QT-R-R relationship provides sufficient information for its use in pharmacological studies. The QT-R-R relationship shows a residual variability in part related to autonomic changes. Therefore, for studies with a crossover design, a single evaluation of the QT-R-R relationship would be appropriate only in the case of stability ANS influences for each study period.

In addition, the QT-R-R relationship might be changed by the drug tested. As a consequence, the QT-R-R relationship obtained in control condition cannot be used as a fingerprint throughout the trial.

\section{REFERENCES}

1. Franz MR, Swerdlow CD, Liem LB, et al. Cycle length dependence of human action potential duration in vivo: Effects of single extrastimuli, sudden sustained rate acceleration and deceleration, and different steady state frequency. J Clin Invest 1988;82:972-979.

2. Viitasalo $M$, Karjalainen J. QT Intervals at heart rates from 50 to 120 beats per minutes during 24-hour electro- 
cardiographic recordings in 100 healthy men. Circulation 1992;86:1439-1442.

3. Funck-Brentano C, Jaillon P. Rate-corrected QT interval: Techniques and limitations. Am J Cardiol 1993;72:17B22B

4. Malik M. Problems of heart rate correction in assessment of drug-induced QT interval prolongation. J Cardiovasc Electrophysiol 2001;12:411-420.

5. Drici MD, Burklow TR, Haridasse V, et al. Sex hormones prolong the QT interval and downregulate potassium channel expression in the rabbit heart. Circulation 1996:94:1471-1474.

6. Macfarlane PW, McLaughlin SC, Devine B, et al. Effects of age, sex, and race on ECG interval measurements. J Electrocardiol 1995;27(Suppl.):14-19.

7. Molnar J, Zhang F, Weiss J, et al. Diurnal pattern of QTc interval: How long is prolonged? Possible relation to circadian triggers of cardiovascular events. J Am Coll Cardiol 1996;27:76-83

8. Bexton R, Vallin HO, Camm AJ. Diurnal variation of the QT interval-Influence of the autonomic nervous system. Br Heart J 1986;55:253-258.

9. Murakawa $Y$, Inoue H, Nozaki A, et al. Role of sympathovagal interaction in diurnal variation of QT interval. Am J Cardiol 1992;69:339-343.

10. Ahmed MW, Kadish AH, Goldberg JJ. Autonomic effects on OT interval. Ann Noninvasive Electrocardiol 1996;1:4453 .

11. Kong $T Q$, Goldberger JJ, Parker $M$, et al. Circadian variation in human ventricular refractoriness. Circulation 1995;92:1507-1516.

12. Browne KF, Prystowsky E, Heger JJ, et al. Prolongation of the QT interval in man during sleep. Am J Cardiol 1983:52:55-59.

13. Bezzina CR, Verkerk AO, Busjahn A, et al. A common polymorphism in KCNH2 (HERG) hastens cardiac repolarization. Cardiovasc Res 2003;59:27-36.

14. Dekker J, Schouten E, Kloutwijk P, et al. Association between QT interval and coronary heart disease in middleaged and elderly men: The Zutphen study. Circulation 1994;90:779-785.

15. Sagie A, Larson MG, Goldberg RJ, et al. An improved method for adjusting the QT interval for heart rate (The Framingham Heart Study). Am J Cardiol 1992;70:797-801.

16. Benhorin J, Merri $M$, Alberti $M$, et al. Long QT syndrome. New electrocardiographic characteristics. Circulation 1990;82:521-527.

17. Extramiana F, Maison-Blanche $\mathrm{P}$, Badilini F, et al. Circadian modulation of QT rate dependence in healthy volunteers. J Electrocardiol 1999;32:33-43.

18. Malik M. The imprecision in heart rate correction may lead to artificial observations of drug-induced QT interval changes. PACE 2002;25:209-216.

19. Hnatkova $K$, Malik M. "Optimum" formulae for heart rate correction of the QT interval. PACE 1999;22:1683-1687.

20. Malik M, Farbom P, Batchvarov V, et al. Relation between QT and RR intervals is highly individual among healthy subjects: Implications for heart rate correction of the OT interval. Heart 2002;87:220-228.
21. Arildsen $\mathrm{H}$, Christiansen EH, Pedersen AK, et al. Reproducibility of QT parameters derived from 24-hour ambulatory ECG recordings in healthy subjects. Ann Noninvasive Electrocardiol 2001:6:24-31.

22. Batchvarov VN, Ghuran A, Smetana P, et al. QT-RR relationship in healthy subjects exhibits substantial intersubject variability and high intrasubject stability. Am J Physiol Heart Circ Physiol 2002;282:H2356-H2363.

23. Lande G, Funck-Brentano C, Ghadanfar M, et al. Steadystate versus non-steady-state QT-RR relationships in 24 hour Holter recordings. PACE 2000;23:293-302.

24. Pueyo E, Smetana $P$, Laguna $P$, et al. Estimation of the QTR-R hysteresis lag. J Electrocardiol 2003;36(Suppl.):187190.

25. Valensi PE, Johnson NB, Maison-Blanche $\mathrm{P}$, et al. Influence of cardiac autonomic neuropathy on heart rate dependence of ventricular repolarization in diabetic patients. Diabetes Care 2002;25:918-923.

26. Karjalaien J, Viitasalo $M$, Manttari $M$, et al. Relation between QT intervals and heart rates from 40 to 120 beats $/ \mathrm{min}$ in rest electrocardiograms of men and a simple method to adjust QT interval values. J Am Coll Cardiol 1994;23:15471553.

27. Pratt CM, Ruberg S, Morganroth J, et al. Dose-response relation between terfenadine (Seldane) and the QTc interval on the scalar electrocardiogram: Distinguishing a drug effect from spontaneous variability. Am Heart J 1996;131(3):472480.

28. International Conference on Harmonisation (ICH): The clinical evaluation of QT/QTc interval prolongation and proarrhythmic potential for non-antiarrhythmic drugs. http://www.fda.gov/cder/calendar/meeting/qt4jam.pdf

29. Badilini F, Maison-Blanche P, Childers R, et al. QT interval analysis on ambulatory electrocardiogram recordings: A selective beat averaging approach. Med Biol Eng Comput 1998:36:1-10.

30. Kligfield P, Lax KG, Okin PM. QT interval-heart rate relation during exercise in normal men and women: Definition by linear regression analysis. J Am Coll Cardiol 1996;28:1547-1555.

31. Demolis JL, Kubitza D, Tenneze L, et al. Effect of a single oral dose of moxifloxacin (400 mg and $800 \mathrm{mg}$ ) on ventricular repolarization in healthy subjects. Clin Pharmacol Ther 2000;68:658-666.

32. Extramiana F, Neyroud N, Huikuri HV, et al. QT interval and arrhythmic risk assessment after myocardial infarction. Am J Cardiol 1999;83:266-269.

33. Neyroud N, Maison-Blanche P, Denjoy I, et al. Diagnostic performance of OT interval variables from 24-hour electrocardiography in the long QT syndrome. Eur Heart J 1998:19:158-165.

34. Extramiana F, Maison-Blanche P, Tavernier R, et al. Cardiac effects of chronic oral beta-blockade: Lack of agreement between heart rate and QT interval changes. Ann Noninvasive Electrocardiol 2002;7:379-388.

35. Funck-Brentano C, Kibleur Y, Le Coz F, et al. Rate dependence of sotalol-induced prolongation of ventricular repolarization during exercise in humans. Circulation 1991;83:536545 . 
APPENDIX 1.

Individual Data: QT Rate-Dependence-Linear Model, $\mathrm{n}=\mathbf{4 1}$

\begin{tabular}{|c|c|c|c|c|c|c|c|c|}
\hline & \multicolumn{4}{|c|}{ Coefficient $\alpha$} & \multicolumn{4}{|c|}{ Coefficient $\beta$} \\
\hline & Week 1 & Week 2 & Week 3 & Week 4 & Week 1 & Week 2 & Week 3 & Week 4 \\
\hline 001 & 0.052 & 0.082 & 0.044 & 0.066 & 377.0 & 332.9 & 378.7 & 355.0 \\
\hline 002 & 0.079 & 0.054 & 0.060 & 0.066 & 337.6 & 359.8 & 347.5 & 357.5 \\
\hline 003 & 0.078 & 0.057 & 0.064 & 0.076 & 298.6 & 320.9 & 321.9 & 305.3 \\
\hline 004 & 0.058 & 0.056 & 0.071 & 0.066 & 303.7 & 315.9 & 297.2 & 296.9 \\
\hline 005 & 0.068 & 0.060 & 0.074 & 0.071 & 343.0 & 346.1 & 333.9 & 333.6 \\
\hline 006 & 0.074 & 0.060 & 0.039 & 0.049 & 319.5 & 334.8 & 357.3 & 342.4 \\
\hline 007 & 0.059 & 0.050 & 0.059 & 0.065 & 313.7 & 320.2 & 310.2 & 311.5 \\
\hline 008 & 0.092 & 0.082 & 0.093 & 0.102 & 311.1 & 329.2 & 320.5 & 326.5 \\
\hline 009 & 0.069 & 0.054 & 0.080 & 0.081 & 293.5 & 308.9 & 288.9 & 296.5 \\
\hline 010 & 0.115 & 0.118 & 0.110 & 0.085 & 291.6 & 294.9 & 307.7 & 326.5 \\
\hline 011 & 0.051 & 0.072 & 0.064 & 0.062 & 361.9 & 352.2 & 343.7 & 354.9 \\
\hline 012 & 0.092 & 0.092 & 0.083 & 0.089 & 288.4 & 289.4 & 308.1 & 302.9 \\
\hline 013 & 0.082 & 0.071 & 0.071 & 0.043 & 328.2 & 345.1 & 333.9 & 381.6 \\
\hline 014 & 0.069 & 0.102 & 0.080 & 0.071 & 317.6 & 288.0 & 317.6 & 332.8 \\
\hline 015 & 0.082 & 0.100 & 0.103 & 0.078 & 294.1 & 274.5 & 278.1 & 293.3 \\
\hline 016 & 0.080 & 0.086 & 0.073 & 0.071 & 327.7 & 319.6 & 338.5 & 340.2 \\
\hline 017 & 0.078 & 0.055 & 0.065 & 0.060 & 318.6 & 359.2 & 343.9 & 343.6 \\
\hline 018 & 0.058 & 0.069 & 0.077 & 0.040 & 371.5 & 365.2 & 349.5 & 403.4 \\
\hline 019 & 0.070 & 0.066 & 0.082 & 0.085 & 358.7 & 364.0 & 347.2 & 336.5 \\
\hline 020 & 0.063 & 0.049 & 0.061 & 0.052 & 323.5 & 342.1 & 329.5 & 336.4 \\
\hline 021 & 0.056 & 0.056 & 0.061 & 0.077 & 351.8 & 352.8 & 346.2 & 330.5 \\
\hline 022 & 0.103 & 0.109 & 0.124 & 0.075 & 316.1 & 316.5 & 298.5 & 347.5 \\
\hline 023 & 0.042 & 0.040 & 0.063 & 0.061 & 373.4 & 366.8 & 334.6 & 331.7 \\
\hline 024 & 0.116 & 0.067 & 0.067 & 0.057 & 278.6 & 334.4 & 330.6 & 347.4 \\
\hline 025 & 0.100 & 0.095 & 0.078 & 0.096 & 331.8 & 334.1 & 352.0 & 328.7 \\
\hline 026 & 0.082 & 0.094 & 0.090 & 0.066 & 335.4 & 326.7 & 327.4 & 358.8 \\
\hline 027 & 0.051 & 0.055 & 0.060 & 0.067 & 345.7 & 338.6 & 329.6 & 315.8 \\
\hline 028 & 0.087 & 0.069 & 0.081 & 0.064 & 313.8 & 331.1 & 312.3 & 349.8 \\
\hline 029 & 0.091 & 0.062 & 0.077 & 0.085 & 311.5 & 337.6 & 326.2 & 317.7 \\
\hline 030 & 0.073 & 0.049 & 0.051 & 0.068 & 374.4 & 413.6 & 411.2 & 379.2 \\
\hline 031 & 0.055 & 0.056 & 0.065 & 0.058 & 372.5 & 361.5 & 355.5 & 368.0 \\
\hline 032 & 0.094 & 0.103 & 0.099 & 0.084 & 310.2 & 299.1 & 306.9 & 318.8 \\
\hline $03 \overline{3}$ & 0.066 & 0.070 & 0.068 & 0.090 & 361.1 & 346.5 & 355.9 & 329.2 \\
\hline 034 & 0.068 & 0.089 & 0.091 & 0.088 & 309.7 & 287.6 & 294.3 & 289.5 \\
\hline 035 & 0.053 & 0.059 & 0.067 & 0.066 & 343.0 & 346.0 & 325.3 & 319.2 \\
\hline 036 & 0.062 & 0.059 & 0.095 & 0.088 & 305.4 & 298.4 & 279.8 & 280.8 \\
\hline 037 & 0.050 & 0.051 & 0.044 & 0.052 & 401.8 & 412.4 & 415.7 & 403.9 \\
\hline 038 & 0.085 & 0.092 & 0.093 & 0.082 & 316.3 & 311.0 & 308.9 & 321.6 \\
\hline 039 & 0.073 & 0.066 & 0.055 & 0.058 & 303.5 & 299.8 & 317.0 & 310.7 \\
\hline 040 & 0.064 & 0.096 & 0.098 & 0.077 & 324.8 & 299.6 & 300.7 & 315.7 \\
\hline 041 & 0.049 & 0.072 & 0.069 & 0.082 & 351.7 & 319.0 & 331.4 & 310.9 \\
\hline
\end{tabular}


APPENDIX 2.

Individual Data: Calculated QT1000-Linear Model, $\mathrm{n}=41$

\begin{tabular}{|c|c|c|c|c|c|}
\hline & Week 1 & Week 2 & Week 3 & Week 4 & Moxi-floxacin \\
\hline 001 & 429.3 & 415.2 & 422.8 & 420.5 & 423.3 \\
\hline 002 & 416.6 & 413.4 & 407.5 & 423.5 & 427.1 \\
\hline $00 \overline{3}$ & 376.3 & 378.0 & 385.9 & 380.9 & 389.1 \\
\hline 004 & 362.1 & 371.5 & 368.0 & 363.2 & 378.5 \\
\hline 005 & 411.1 & 406.6 & 408.1 & 404.5 & 418.6 \\
\hline 006 & 393.7 & 395.3 & 396.6 & 391.6 & 392.1 \\
\hline 007 & 373.2 & 369.8 & 369.4 & 376.5 & 384.6 \\
\hline 008 & 403.0 & 411.2 & 413.6 & 428.6 & 431.6 \\
\hline 009 & 362.7 & 362.9 & 369.3 & 377.1 & 365.4 \\
\hline 010 & 406.4 & 412.9 & 418.0 & 411.8 & 415.4 \\
\hline 011 & 413.3 & 424.2 & 407.6 & 416.7 & 428.8 \\
\hline 012 & 380.1 & 381.6 & 391.3 & 392.3 & 400.7 \\
\hline 013 & 410.6 & 416.2 & 404.9 & 424.4 & 419.1 \\
\hline 014 & 386.5 & 390.1 & 398.1 & 404.1 & 406.4 \\
\hline 015 & 376.5 & 374.9 & 381.2 & 371.0 & 380.5 \\
\hline 016 & 407.3 & 405.5 & 411.9 & 411.2 & 408.4 \\
\hline 017 & 396.1 & 414.2 & 409.2 & 403.2 & 402.5 \\
\hline 018 & 429.6 & 434.0 & 426.5 & 443.2 & 426.4 \\
\hline 019 & 428.6 & 429.9 & 429.3 & 421.3 & 429.8 \\
\hline 020 & 386.8 & 391.0 & 390.9 & 388.5 & 396.1 \\
\hline 021 & 408.3 & 409.1 & 407.3 & 407.4 & 409.7 \\
\hline 022 & 419.4 & 425.3 & 422.1 & 422.1 & 426.5 \\
\hline $02 \overline{3}$ & 414.9 & 406.7 & 397.7 & 393.2 & 403.8 \\
\hline 024 & 394.3 & 401.0 & 397.3 & 404.3 & 399.4 \\
\hline 025 & 432.3 & 428.9 & 430.1 & 424.2 & 434.9 \\
\hline 026 & 417.7 & 420.7 & 417.9 & 424.8 & 421.1 \\
\hline 027 & 396.7 & 393.4 & 389.4 & 382.8 & 398.9 \\
\hline 028 & 400.3 & 399.7 & 393.2 & 413.7 & 407.3 \\
\hline 029 & 402.1 & 399.4 & 402.9 & 403.1 & 403.5 \\
\hline 030 & 447.0 & 462.4 & 461.9 & 447.6 & 463.8 \\
\hline 031 & 427.6 & 417.7 & 420.6 & 426.4 & 431.5 \\
\hline 032 & 404.1 & 401.9 & 406.0 & 403.1 & 414.2 \\
\hline 033 & 426.8 & 416.2 & 424.2 & 419.4 & 426.1 \\
\hline 034 & 377.7 & 377.0 & 385.5 & 377.3 & 374.4 \\
\hline 035 & 395.5 & 404.5 & 391.9 & 385.2 & 396.6 \\
\hline 036 & 367.7 & 357.2 & 374.5 & 368.3 & 378.8 \\
\hline 037 & 451.6 & 462.9 & 459.8 & 456.1 & 455.7 \\
\hline 038 & 401.0 & 403.2 & 401.7 & 403.6 & 408.3 \\
\hline 039 & 376.4 & 366.2 & 372.0 & 369.1 & 372.3 \\
\hline 040 & 388.8 & 395.4 & 398.5 & 392.6 & 405.1 \\
\hline 041 & 400.8 & 391.1 & 400.0 & 392.5 & 399.8 \\
\hline
\end{tabular}

